\title{
Systematic conservation planning and adaptive management
}

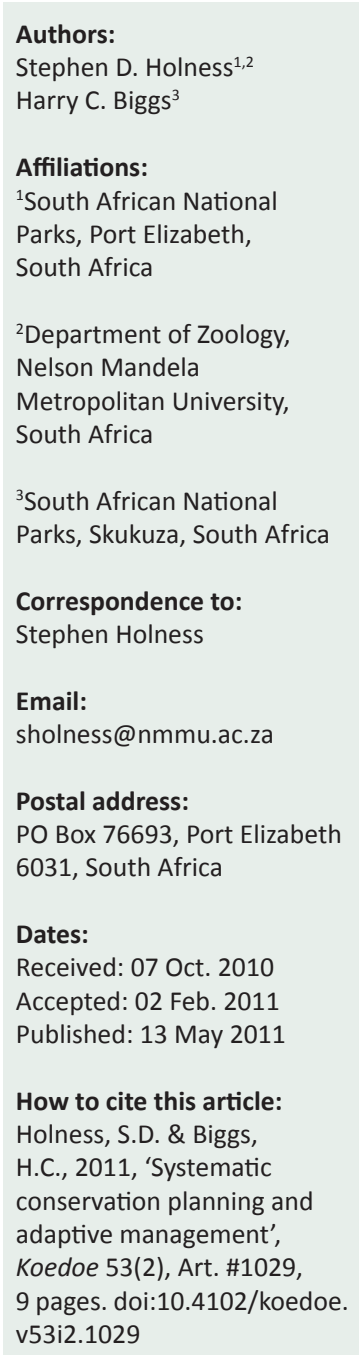

\section{Authors:}

Stephen D. Holness ${ }^{1,2}$

\section{Affiliations:}

South African Nation

Parks, Port Elizabeth

Nelson Mandela

Metropolitan University,

${ }^{3}$ South African National

Correspondence to:

Email:

Postal address:

PO Box 76693, Port Elizabeth

Dates:

Accepted: 02 Feb. 2011

How to cite this article: Holness, S.D. \& Biggs,

H.C., 2011, 'Systematic adaptive management', 9 pages. doi:10.4102/koedoe. v53i2.1029

(C) 2011. The Authors. Licensee: OpenJournals Publishing. This work is licensed under the Creative Commons Attribution License.
This article argues that systematic conservation planning (SCP) is an intrinsic part of the adaptive management approach within SANParks and should not be seen as a separate or different initiative. SCP operates within a complex environment that requires a deliberately adaptive approach. The similarities in philosophy, structure and functional elements of the planning process and approach between adaptive management and SCP, as applied within SANParks, are highlighted. The article distils requirements for ensuring that SCP remains strategically adaptive in its approach.

Conservation implication: A deliberately adaptive approach to SCP improves its effectiveness in guiding the implementation of conservation actions and is a requirement for effective conservation planning in a complex environment.

\section{Introduction}

In the last decade, conservation planning in South Africa (e.g. Cadman et al. 2010; Cowling et al. 2003a; Cowling et al. 2003b; Driver et al. 2005) has been strongly influenced by the principles of systematic conservation planning (SCP) (Margules \& Pressey 2000). South African National Parks (SANParks) is an important participant in this planning, which takes place at nested spatial scales in the country. It involves their entrusted conservation estate, the surrounding seascapes, landscapes and riverscapes in which the parks are embedded, and the planned future expansion of existing and new protected areas. Specific theme areas where SCP principles underlie SANParks' spatial planning processes include the zoning, land use and infrastructure planning within reserves, the spatial planning for the buffer areas and areas of influence around parks, and the planning for identifying reserve expansion priorities for all existing national parks and evaluating potential areas for new national parks. SCP principles and processes have been applied in a range of environments, including terrestrial, freshwater and marine areas, and underpin the response strategies of conservation agencies to key threats such as climate change and habitat fragmentation around reserves. Concurrent with the SCP process (which has largely focused on spatial planning issues), SANParks has actively developed a strategic adaptive management (SAM) programme, which is the conceptual basis that underpins biodiversity management within reserves (Rogers 2005; South African National Parks 2008). Adaptive management is an attempted response to the uncertainties of the operating context in an environment of complexity (Levin 1999) and SAM (Rogers 2005), with its flexible goal-based view, should be well suited for planning in a complex situation.

The importance of an adaptive approach to SCP has been highlighted, at least in theory, by conservation planners (Bottrill \& Pressey in prep.; Fischer et al. 2009; Grantham et al. 2010; Groves 2003; Knight, Cowling \& Campbell 2006; Margules \& Pressey 2000; Pressey \& Bottrill 2009; Salafsky et al. 2002). Despite a monitoring and evaluation stage being one of the original six SCP steps laid out by the influential paper of Margules and Pressey (2000), which also highlights the need for an iterative and adaptive approach, there appears to be little evidence that SCP is actually practiced in an adaptive manner. A recent literature search ${ }^{1}$ failed to identify a single documented example of a functioning SCP system that fully integrates adaptive management principles. Whether the lack of examples of functioning adaptive SCP systems is the result of poor documentation or an indication of SCP not being generally adaptive in practice, is uncertain. In either case, it is valuable to highlight the SANParks approach to SCP where it forms an intrinsic part of adaptive management.

This article argues that SCP is, in fact, being practiced in an increasingly adaptive manner within SANParks and that SCP and SAM should not be seen as being separate and unrelated processes. We firstly outline the rationale for why adaptive planning approaches are necessary within SCP

1.Conducted January 2011 on Google Scholar and Science Direct using the keywords 'systematic conservation planning' and 'adaptive management', and examining all papers which had references to both concepts. 
and then discuss similarities in the underlying philosophies of SCP and SAM as used by SANParks, point out similarities in structure and components between the planning processes employed, examine existing or potential parallels in application, and conclude by discussing how we may ensure that SCP remains appropriately adaptive. Emphasis is given to SCP-related examples (the ones normally in deficit when it comes to demonstrating adaptiveness) and diagrams, but with parallel detail for SAM to support the intention of the article. The article is designed to document the lessons learnt from the SANParks experience in practically applying SCP in an adaptive manner within the context of a broader SAM system. Where possible, specific projects and outputs are referenced, but most remain unpublished or in inaccessible, grey literature.

\section{Why an adaptive approach is required in conservation planning}

The physical, social, political, technological and economic environments in which SCP takes place are changing - and, in South Africa, often rapidly. Process relationships in such socio-ecological systems (Berkes, Colding \& Folke 2003) are often poorly understood, unpredictable and evolving themselves. In the business domain, Snowden and Boone (2007) have emphasised the difference between complicated and complex systems. The former refers to systems with a large number of parts but which display predictable behaviour (e.g. an aircraft or a circuit board), whilst the latter refers to a system with any number of parts, but for which dynamic relationships and interactions dominate in a way that can produce surprises (e.g. ecosystems and most socioecological systems). 'Complexity' has a variety of related technical definitions and leading complexity thinker, Paul Cilliers (2000), finds it useful rather to summarise the general characteristics of a complex system for user disciplines: he emphasises influential nonlinear interactions between the multiple elements of a system(which is invariably open), organised as direct and indirect feedbacks. Because of the importance of these interactions, system behaviour as a whole cannot be predicted from inspection of the components alone. History of antecedent configurations is also very important in determining future trajectories. Furthermore, these systems can reorganise their internal structure without the intervention of an external agent; that is, they tend to be adaptive. In the biological and ecological sciences, thinking towards complexity has received growing attention. Levin (1999) used the diagnostic that systems with diversity, interactions (especially local interactions) and any selection process (such as natural selection) - precisely the kind of systems widely encountered in these fields would show complex behaviour. Resilience thinkers (e.g. Gunderson \& Holling 2001), along with those in fields that focus on sustainability and transdisciplinarity, emphasised adaptive and often heuristic responses as appropriate for learning to cope effectively in managing complex systems, which are often depicted as socio-ecological systems. At the level of the philosophy of science, Ulanowicz (2009) argues that ecology can add to (and reorganise) earlier Newtonian and Darwinian views with new and useful generalities. This results in society dealing more humbly, and ultimately more effectively, with many types of irreducible uncertainty in (in his cases, biophysical) systems, which nevertheless show propensities of pattern that can indeed be usefully understood. Against this background it is not surprising that adaptive strategies, difficult though they are to operationalise, are being promoted widely in these fields today.

If one specifically examines the environment within which SCP operates and plans, there is much evidence that this environment should be seen as complex:

- Both biodiversity itself and the associated human interactions are changing rapidly (Pressey et al. 2007).

- There are many steps, often with only partly predictable outcomes, involved in the generation and ultimate implementation of SCP.

- SCP takes place across multiple agencies (e.g. national and provincial conservation agencies, water affairs, agriculture, marine management agencies).

- SCP needs to engage diverse stakeholder groups (ranging from traditional communities living largely subsistencebased lifestyles on park boundaries to organised industry such as commercial agriculture or fisheries).

- SCP deals with multiuse landscape mosaics and river catchment networks.

- SCP deals with interactions between government-driven processes on the one hand (e.g. land reform) and freemarket entities on the other (particularly individual land owners).

- In the context of a conservation organisation, recommendations that stem from SCP processes are implemented through a range of mechanisms, including land purchase, voluntary land stewardship programmes and proactive land use planning (e.g. through guiding regional zoning processes), as well as being used to respond reactively to development proposals (e.g. through environmental impact assessments).

- Experience indicates that there are often unexpected setbacks (e.g. large reductions in the budget available for land acquisition or changes in institutional capacity or willingness to expand) and surprising windfalls (e.g. sudden availability of high-priority conservation sites due to the death of a land owner or the auction of an insolvent estate).

- There is often imperfect knowledge of many aspects(e.g. willingness of land users to be involved in a stewardship programme or to sell their land for incorporation into a reserve) and of the viability of different land uses, let alone imperfect knowledge of the multiple perceptions and mental models held by different people in this regard.

If political fickleness, evolution of human values and fluctuating levels of capacity are added as additional attributes, it seems clear that the system is complex. Yet, in many cases, we come from a history of viewing such systems simplistically, for example by assuming that there is a single, stable planning approach that will result in an optimal park blueprint for a region (as would be 
applicable in a 'complicated' world). As corollaries, we have often assumed that if we only had more data, we would eventually understand the whole system adequately and that a discrete handover from 'planners' to 'implementers' would be possible. In reality, if we accept and internalise the complexity described above along with its consequences, we need to alter our approach. On the other hand, however, we cannot allow ourselves to become paralysed by this complexity and should thus seek the requisite simplicities that allow for action and further learning (Stirzaker et al. 2010). The use of SCP in SANParks has led to some such adaptation and learning already, and more will follow. Such learning provides the basis for the subsequent analysis in this article. Whilst broad-level plans may be useful to give society a rough idea of where to conserve land or how to manage it, intermediate and finer-scale planning appear to require more adaptive capacity and response to allow successful navigation (Berkes et al. 2003) of the complexity so that both conservation and broader sustainable land use goals can be reached.

Having discussed why an adaptive approach should be considered appropriate for SCP in our (and likely most) circumstances, we now examine more specifically possible underlying and operating similarities between SAM and SCP, with reference to several SCP examples. Multiple examples of SAM are described in this volume (including management of river systems, fire and alien invasive species), with an introductory editorial (Roux \& Foxcroft 2011), sketching the context.

\section{Similarities in philosophy}

SAM and SCP share some fundamentally similar intentions and much underlying philosophy. Although the similarities mentioned below were presented in the original SCP texts (e.g. Margules \& Pressey 2000), certain of these issues have been made more explicit in recent renditions (Bottrill \& Pressey in prep.; Pressey \& Bottrill 2009), such as feedback loops being incorporated into key diagrams.

SCP and SAM both take a wide view of the stakeholder base and strive to be inclusive. Bottrill and Pressey (in prep.) emphasise the importance of the early identification and involvement of stakeholders in the SCP process. These stakeholders can include other conservation agencies, governments, NGOs, experts and communities. Within SANParks, a recent example is the planning of the marine protected area associated with Addo Elephant National Park (on the south-eastern coast of South Africa), which included stakeholders such as commercial fisheries, recreational fishermen, local property owners' associations and subsistence fishers. Stakeholder participation has included targeted meetings with specific sectors as well as public participation. Another example is a feasibility study led by SANParks for a new protected area in the Southern Drakensberg, which has had direct representation of local authorities, agriculture, conservation organisations and government bodies such as the Department of Environmental Affairs and the South African National Biodiversity Institute.
Whilst stakeholder mapping is less explicitly described in the headline procedures of SAM, stakeholder participation is intrinsic to SAM processes such as development and implementation of national park management plans. The consistent success of this SAM-based initiative relies on the identification and involvement of a broad cross section of stakeholders, with particular emphasis on local government structures, interest groups, local communities and park forums. The latter acts as a particularly useful vehicle for the public to contribute to park decision making (A. Symonds; pers. comm.).

Key benefits of the strong emphasis on stakeholder involvement include the development of a 'shared rationality' (Rogers 2005) amongst stakeholders and increased trust and credibility amongst key partners. For example, the feasibility study in the Southern Drakensberg included both national and provincial conservation agencies, which have in the past been drawn into unproductive disputes over the implementation of projects that had originated separately (M. Knight; pers. comm.). Other benefits include:

- access to implementation opportunities that would otherwise not be available (e.g. alignment with payment for ecosystem service projects or land reform initiatives)

- improved understanding of the requirements and concerns of stakeholders (e.g. the marine planning process around Addo Elephant National Park now includes the identification of areas which various fishing industries are most concerned about for the impact of the closure of certain areas)

- support from a range of organisations that are responsible for implementing conservation actions (e.g. catchment management agencies, local authorities, environmental impact assessment implementing authorities).

Both SCP and SAM processes recognise the importance of societal and organisational values and attempt to elicit these values and incorporate them in the planning process. Pressey and Bottrill (2009) identify the establishment of clearly defined goals as a key component of a number of divergent conservation planning processes. These broad goals are driven by societal and organisational values. For example, in an SCP process for a reserve, these goals may influence the relative value of biodiversity, heritage and tourism features, or the extent to which a reserve would be planned to minimise impact on economic productivity (e.g. displacement of viable resource extraction industries or land uses) or social systems (e.g. displacement of farm workers). As part of its overall SAM thrust, SANParks developed a clear set of conservation values (SANParks 2008); the adaptive planning procedures in SAM (Rogers 2005) highlight these and other wider societal values as mandatory and key inputs in the formulation of, for example, park objectives. Both SCP and SAM thus strive to balance a range of societal values in reaching decisions and clearly recognise that in most cases the appropriate management responses are driven not by biodiversity considerations only.

Both SCP and SAM strive for integration across sectors (e.g. conservation, agriculture, forestry, mining and water 
management) and see biodiversity as only one important attribute within a wider view of societal interests, usually within multiuse landscapes. It is clearly recognised that collaboration between a range of sectors are needed for successful implementation to result in the desired outcome (e.g. a resilient system within which a reserve is nested in a matrix of compatible land uses). For example, in SCP for reserve expansion, the desired outcome of ensuring that freshwater systems which flow into a reserve remain in or are restored to an acceptable desired state, depends entirely on upstream users, including forestry and local authorities. This parallels what is strived for in other SAM-based initiatives in SANParks, such as ongoing river management in park plans.

Both SCP and SAM accept that recognition of complexity is paramount to success. The SAM process is explicitly designed to accommodate and operate in a complex environment. Although some (older) SCP projects were undertaken to produce once-off blueprints for reserve expansion, SANParks soon recognised that planning products had to remain 'live' to ensure their adapting and response to complex and changing environments. For example, for Addo Elephant National Park, a systematic reserve expansion study was commissioned from outside service providers. Although a good quality product was delivered (Council for Scientific and Industrial Research 2002), it soon became clear that a single static plan for the park was not particularly useful for park expansion implementation. The base data from this project were then incorporated into an internal decision support system housed within the newly established SANParks Park Planning Department. This allowed for response to changes in the implementation environment (e.g. specific properties may have been successfully acquired or negotiations may have fallen through for others), improvements in data (e.g. revision and refinement of land use, land transformation and degradation data), refinements of methodology (e.g. revision of targets or reprioritisation of properties based on emergent considerations) or review of value systems.

A key difference may be that SAM has broad overall applicability to a range of planning, management and decision making situations, whilst SCP is a more focused spatial planning tool for a particular task. In this sense we could argue that SCP may philosophically be seen as nested inside SAM. We thus promote the idea that SCP should generally fall inside the broader SAM philosophy. This article discusses the extent to which this does, and should, take place, by considering similarities not only in philosophy but also in structure and process, and then reviewing whether SCP implementation proceeds in a way that can be considered SAM compliant in reality.

\section{Similarity in structural and functional components}

SAM, as practiced in SANParks, has a number of clearly articulated stages and processes, of which the adaptive planning process serves as a usual start (Figure 1). Although SCP can vary widely with regard to its objectives, process, data and approach, some themes, stages and processes are common to most of its planning strategies. The IUCN initiative on conservation planning convened by the Species Survival Commission and World Commission on Protected Areas identifies 11 major stages within an SCP process (Bottrill \& Pressey in prep.; Pressey \& Bottrill 2009), as shown in Figure 2. Here we explore the similarities between SAM and the SCP process with regard to their structural and functional components and the overlap of various components, with specific reference to how the SCP process is applied in SANParks.

The initial stages of a SAM process are aimed at defining the decision making environment within which adaptive management is to take place (Figure 1). Specific components of this process include defining a vision and explicitly identifying the operating principles and context within which management takes place. These steps implicitly require intensive internal and external stakeholder involvement, which, in practice, enhances the credibility of the process and ensures that it meets legislative requirements and is sensitive to stakeholder needs. The process of defining a vision involves a broad philosophical statement of intent that is clearly linked to the values of the organisation, whilst the operating principles refine these more specifically. The exploration of context examines the range of circumstances that affect the decision making process, including local conditions and surroundings. This leads into a series of steps where the vital attributes (or key features) of the system are identified, along with the main influencing factors and possible threats. Very similar stages exist in SCP and SAM, both with regard to how the process is generally conceptualised (Figure 2) and how it is applied within SANParks in practice. Stage 1 of the SCP process involves scoping and costing the planning process, which defines the way the project will be implemented. Key issues include determining a planning domain and identifying the scope and scale at which planning will take place. Although this is sometimes, wrongly, seen as a trivial stage, careful consideration of these issues can result in significant implementation benefits. For example, what would have been systematic assessments for buffer regions around Agulhas and Bontebok National Parks were expanded into a systematic assessment of biodiversity priorities for the whole Overberg district. This resulted in a Critical Biodiversity Map for the district, which embeds the local park concerns into regional requirements and accesses a far broader range of implementation agents (e.g. the provincial conservation agency and local authorities) and additional resources that support more detailed planning than would otherwise have been possible.

Stage 2 of the SCP process involves identifying and involving stakeholders. As discussed earlier, these stakeholders can include other conservation agencies, NGOs, local government, experts and local communities. This process is important for developing trust amongst key partners, accessing a range of implementation opportunities, developing an understanding of stakeholders' requirements and concerns, and obtaining the support of implementing organisations (Pressey \& Bottrill 2009). 


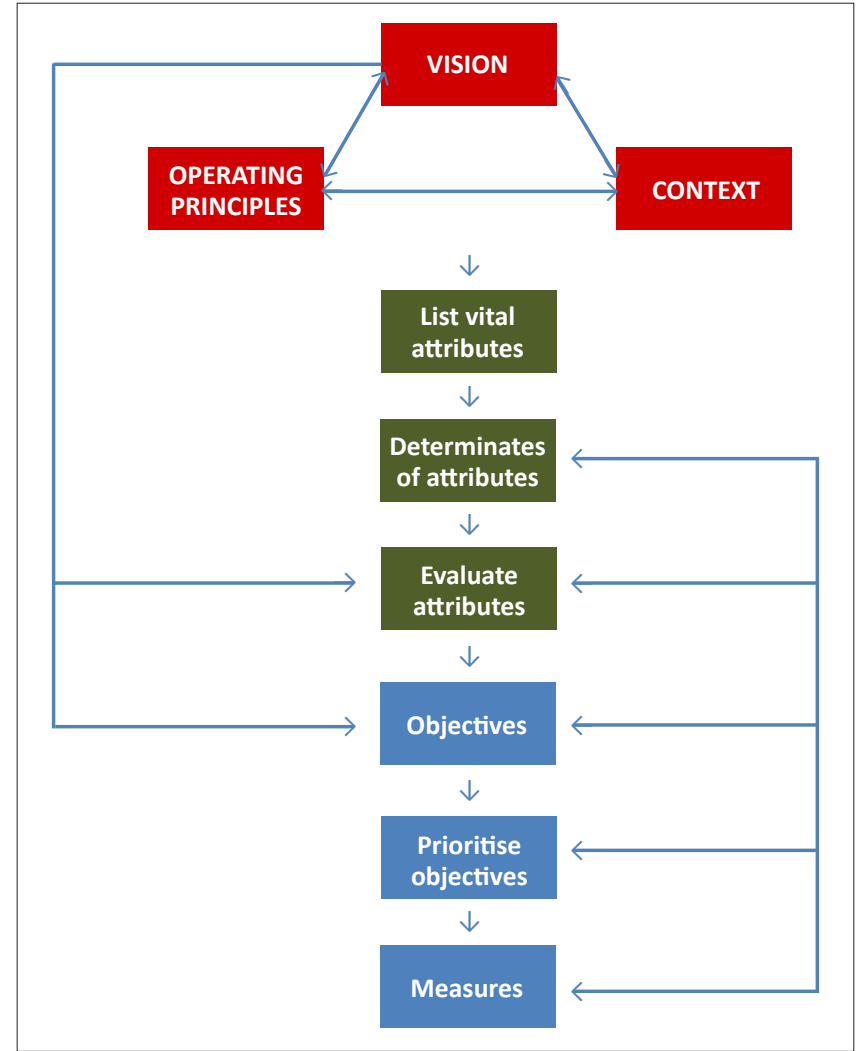

FIGURE 1: Flowchart of the stages of the adaptive planning component of a strategic adaptive management process (adapted from Rogers, K.H., 2005, Biodiversity custodianship in SANParks: a protected area management planning framework, Report to South African National Parks, Pretoria).

Stage 3 of the SCP process provides the context for the subsequent conservation planning steps. The social, economic and political setting within which conservation planning takes place is examined and direct threats (e.g. landcover change or overgrazing in particular areas) as well as indirect threats to natural features (e.g. policies that result in environmental degradation) intended for conservation are examined. Thus, SCP displays clear parallels with SAM in the explicit consideration of the social, economic and political context within which it takes place, the deliberate involvement of stakeholders and the examination of the key features of a region and possible threats.

The context examination phases of both SAM and SCP are followed by a process to identify objectives or goals. In SCP, conservation goals are often initially defined as broad qualitative statements that link the underlying values on which conservation efforts are based to more specific quantitative biodiversity targets (Pressey \& Bottrill 2009). These goals may include ensuring that a reserve includes a representative sample of all the habitats and species in a region, or that the ecological processes on which the reserve depends are sufficiently safeguarded (e.g. ensuring that freshwater inputs from catchment areas are of sufficient quality and quantity or that ecological corridors with neighbouring reserves are not excessively impacted). Later in the SCP process (Step 7, after intermediate steps for gathering spatially explicit data on biodiversity and socioeconomic features and threats), these broad goals are refined to more specific conservation objectives. The use of explicit and generally quantitative targets forces planners to be clear about the required outcomes (analogous to the objectives and thresholds parts of a 'desired state' in SAM), and provides measures against which progress towards targets can be measured. These objectives reduce the potential for ad hoc decisions and form the basis for long-term monitoring and evaluation. In addition to these quantitative goals, qualitative goals are also often set. These may relate to improving the connectivity between reserves or their shape and configuration. This process strongly resembles the SAM process of defining an objectives hierarchy, which starts off with fairly broad objective statements at a high level, and refines these to very specific, and often quantified, low-level objectives (Roux \& Foxcroft 2011). At the end of this process in both SAM and SCP, clear, generally quantifiable objectives exist against which both the current state and the success or failure of management actions can be evaluated. In SCP these objectives are commonly articulated as targets or thresholds (e.g. at least $x$ hectares of this habitat kept in a natural or nearnatural state, or incorporated into a reserve), whilst SAM (for biodiversity objectives at least) tends to define the acceptable end state in terms of thresholds of potential concern (Roux \& Foxcroft 2011), such as a water quality measure that needs to be kept within a specific range. Although not identical, these concepts clearly have a very similar basis. In both SAM and SCP, there is concern not just when a threshold or target is exceeded, but also when the trajectory of that variable suggests that a threshold may be exceeded in the future.

SCP and SAM then both have an operationalisation or implementation phase. In SCP, stages 8-10 involve the evaluation of the current situation (e.g. a reserve network) against the objectives (e.g. quantitative targets for protection of a range of vegetation types or habitat requirements for a particular range of species), the identification of additional priority areas (e.g. for reserve expansion or for coverage

1. Scoping and costing the planning process

FIGURE 2: Conceptual framework for systematic conservation planning developed by the IUCN Initiative on Conservation Planning (diagram adapted from Pressey, R.L. \& Bottrill, M., 2009, 'Approaches to landscape- and seascapescale conservation planning: convergence, contrasts and challenges', Oryx 43(4), 464-475. doi:10.1017/\$0030605309990500). 
by stricter land use controls), and then the implementation of these place-specific actions (e.g. through purchasing a property for inclusion into a reserve or the contractual inclusion of that land). Although this is diagrammatically represented as a mostly linear system, it includes a number of iterations and feedback cycles in practice. For example, the successful purchase of a property could result in the relative value of the remaining properties needing to be reevaluated. Alternatively, properties may not be available owing to changes in willingness of the land owner to sell or socio-economic developments. Once established, it would be necessary to evaluate whether the expanded reserve network did in fact maintain the biodiversity features it was designed to protect in the required state. Alternatively, where the SCP process was aimed at land use planning and controls, the area would need to have been evaluated regularly to ensure that the identified priority areas in a region were in fact appropriately protected and had not been lost to development. In either case, the results of this monitoring and evaluation would need to have been fed back into an ongoing planning and implementation process to ensure that the necessary adjustments were made to the identified priority areas, the implementation mechanisms used and the ongoing planning process itself. In SAM, these stages involve the identification of appropriate management actions (e.g. a changed burning regime), implementing these actions and then evaluating the biodiversity outcome against the applicable thresholds of potential concern (Roux \& Foxcroft 2011). Although the SCP diagram (Figure 2) is summarised as a broadly linear sequence, these steps are, in reality, iterative, overlapping and interlinked. Further, although adaptive cycles and feedbacks are identified at specific places in the planning process in the diagram, these in fact take place so frequently in the process that the diagram suggests a more linear process than exists in practice, at least where SCP is embedded with conservation organisations. It would be helpful for our use if such iterations were made even more explicit in these diagrams.

Overall, there are thus strong structural and functional similarities between SCP and SAM, namely:

- an emphasis on clearly defining the context within which they operate

- explicit consideration of a range of issues such as social and economic factors (as well as biodiversity)

- dependence on stakeholder involvement and full consideration of stakeholder issues

- initial broad higher-level goals which are then refined to more explicit lower-level targets

- explicit monitoring and evaluation stages with feedbacks and learning (in SAM, and increasingly also in SCP, ongoing learning is regarded as imperative, regardless of success or failure).

With all these adaptive and potentially adaptive processes in SCP outlined above, it would be instructive to consider the extent to which, as a whole, SCP actually functions adaptively.

\section{Adaptive implementation of systematic conservation planning in a messy world}

Intuitively, it might seem most logical to conceptualise the SCP process as a series of planning steps that starts with broad-scale planning and eventually cascades down to detailed fine-scale projects (Figure 3). The plans would be spatially nested within one another and specific local projects (e.g. planning for infrastructure within a reserve) would reflect both the values and broad spatial priorities identified by national and regional planning.

However, in our experience, this system does not (and usually cannot) materialise for a number of reasons. Firstly, knowledge is incomplete and generally insufficient for useful top-down planning. Secondly, immediate requirements (e.g. a specific land parcel for reserve expansion becomes available and rapid answers are required as to whether it is strategically valuable), implementation opportunities (e.g. a short window of opportunity may be available to include biodiversity into local the Spatial Development Framework to guide land use planning decisions for a five-year period) and short-term implementation actions (e.g. land use and zoning planning for short-duration poverty relief projects) all hinder the hypothesised 'ideal' implementation in Figure 3. Thirdly, external drivers of project implementation processes (e.g. new requirements and deadlines brought about by government policy or legislative change) or requirements linked to individual projects or initiatives (e.g. a landscape initiative may require a fine-scale assessment of biodiversity priorities for a particular area to support a range of conservation implementation mechanisms, and this may be required before broad national identification of priorities has been undertaken) may require specific planning projects at particular scales for a region to be done as a priority. Fourthly, the planning effort in a region is not limited to a particular organisation and the needs and resources of a number of organisations need to be accommodated and utilised. The specific planning work may also be undertaken within different organisations, with varying time availability. Fifthly, limited resources preclude fully comprehensive top-down planning. Finally, as an important overarching comment, the overall environment being dealt with is complex and neat, linear planning processes generally do not respond ideally to this environment at the range of operative scales.

In practice, within SANParks (and probably more widely in South Africa) the conservation planning process more closely resembles Figure 4.

Within a region the conservation planning would be undertaken by a range of organisations (e.g. academic institutions, national institutes or consulting agencies). Early projects for expansion of specific reserves are not necessarily undertaken at a broad national scale; in fact, much of the initial work tends to be undertaken for biomes or focuses at a very local scale. For example, CAPE for the fynbos (Cowling et al. 2003a) and STEP for the thicket (Cowling et 


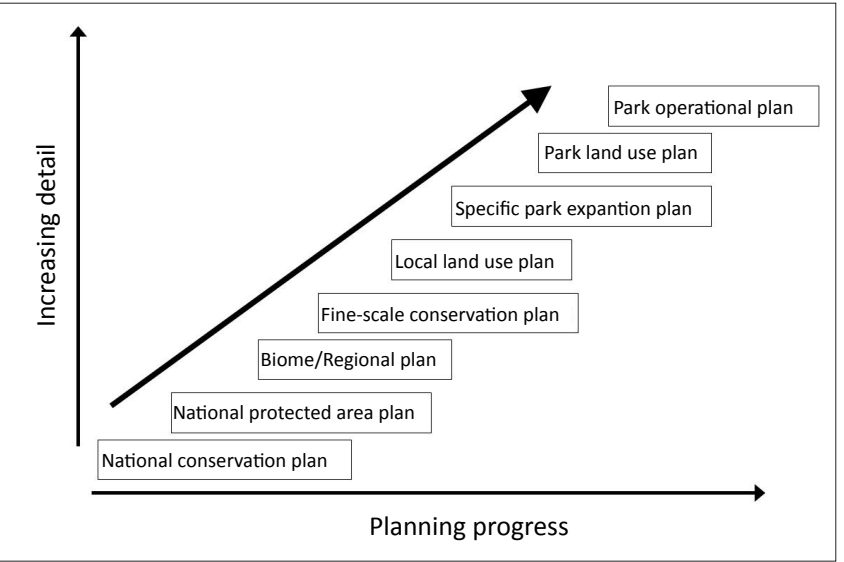

FIGURE 3: Theoretical progression of nested systematic conservation planning processes.

al. 2003b) were done before any national integration had occurred. Later projects, which theoretically should predate the specific expansion plans for a particular reserve, are often completed only after a range of specific reserve expansion plans have been drawn up, as, for example, in the case of the National Protected Areas Expansion Strategy (Government of South Africa 2010). This approach may well result in a mess of overlapping and conflicting blueprints, with no spatial or strategic cohesion. However, in practice, the approach outlined here can produce a highly responsive system that adapts quickly to implementation requirements, learns from the successes and failures of earlier processes, and incorporates both the values derived from broader integrative processes and the specific conservation priorities identified by local-scale planning. In our view, the reason for the success of this system is that the deliberate adaptive approach taken within SANParks and other organisations allows the process to tend towards robustness rather than fragmentation.

There are a number of key elements that contribute to the development of a functional adaptive system. Firstly, planning projects do not aim to be perfect. There is a strong prototyping approach applied in SANParks, which aims to deliver sufficiently good answers (the so-called ' $80 / 20$ principle', meaning that $20 \%$ effort produces $80 \%$ of the result) for specific programmes and projects. The approach is to support implementation by rapidly integrating the best reasonably available data (rather than striving for a perfect product) into efficient decision support systems. Secondly, there are strong adaptive feedbacks between the various components of the system. Each project contributes knowledge or techniques or helps refine values. Thirdly, there is a fairly small community of SCP practitioners who generally know one another, are aware of new methods developed by the others, share data, and interact reasonably frequently (National processes such as an annual Biodiversity Planning Forum organised by the South African National Biodiversity Institute have significantly contributed to the maintenance of dialogue between practitioners). Fourthly, limited budgets and resources have forced projects to utilise the best data and outputs from previous projects, rather than having the scope to go out and develop a whole new suite of products. Lastly, the projects have all been implemented in the same conceptual environment and have strong unifying concepts, namely systematic target-driven or threshold-

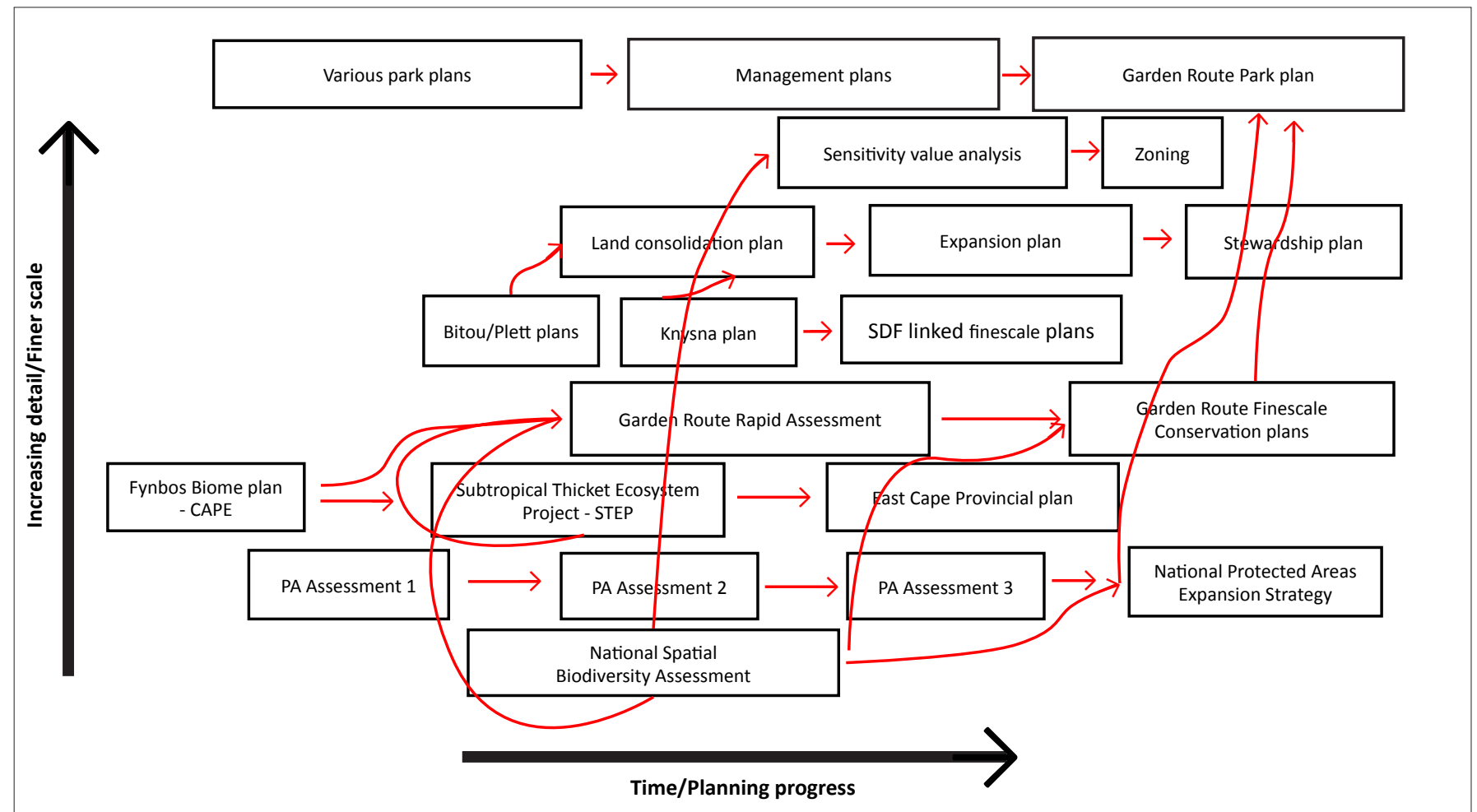

The diagram outlines some of the SCP processes undertaken in, or relevant to the Garden Route. Note that not all of the blocks represent planning undertaken within SANParks. Arrows indicate some places where there are strong learning components that lead from one project into another.

FIGURE 4: Example of an actual planning process. 
driven conservation planning that strives for pattern and process goals to meet in a way that is least conflicting with other land use.

Given that we have examined similarities between SCP and SAM, and how adaptively SCP has been able to perform in the 'messy' real world, we now try to extract a few essential principles that we believe will assist us in maintaining and promoting appropriate adaptiveness in SCP in the future.

\section{Maintaining and promoting adaptive thinking in systematic conservation planning}

Whilst there may be occasional situations where nonresponsive behaviour is desired in SCP (e.g. where an organisation may need a stable blueprint to implement a specific action for a particular period, such as in applying land use controls), this article concentrates on how appropriate levels of adaptive capacity and action can be achieved. Five factors are synthesised below as key strategies.

Development of a prototyping approach: Always insisting on comprehensiveness and full accuracy is unlikely to facilitate implementation. For example, if prototypes are not available, important windows of opportunity for delivering a product in time to influence a broader development plan may be missed. In the Garden Route (Figure 4), rapid systematic plans were developed as precursors to a robust fine-scale conservation plan (Holness, Bradshaw \& Brown 2010; Vromans et al. 2010) to ensure that the major priorities were embedded into regional land use plans that were up for review, as well as environmental management frameworks that were being developed. This does not mean that serial prototyping activities should not be constructed to achieve comprehensive goals with products of increasing quality (e.g. for the Garden Route a formal published product was eventually produced). We recognise that there are ultimately trade-offs between flexibility (such as capacity for frequent updates and maintenance of 'living products') and stability, and believe it important for the SANParks SCP initiatives to try to stay as near to the flexible edge as possible without losing stability.

Encouraging ongoing and explicit learning: If management decisions are not seen as learning opportunities and results of recommendations and decisions are not being assessed and reflected upon in an effective way, the central engine for adaptation starts turning more slowly. Properly functioning feedbacks are essential to such learning. One way of enhancing learning opportunities is by explicitly setting up contrasting management options.

Development of sufficient adaptive capacity for action and learning: This includes having a critical mass of skills available, in people who are or are becoming philosophically geared towards such adaptation. This does not include only experts, but also asks for increasing recognition from at least key stakeholders. Without this capacity, it is likely that successful adaptation will eventually grind to a halt. We recognise that lack of capacity is often given as a reason for inaction. We consider the better attitude to inculcate to be that if limited resources are anticipated for the foreseeable future, maximal adaptive capacity within the limits of the system's means should carefully be planned for.

Maintenance of appreciation for complexity and appropriate attitudes: If both of these are not actively engendered, many individuals may 'roll back': owing to setbacks in dealing with complexity, they become disheartened and go back to historic patterns of behaviour, even where these have been shown unlikely to be effective in dynamic natural resource or biodiversity settings. A common consequence of internalisation of complexity is that people develop a more modest disposition - and such people seldom tout a single option as 'the answer' under all circumstances.

Shared understanding between groups: If knowledge and derived wisdom do not spread amongst academics, planners, implementers and managers, overall goal achievement inevitably drops. Barriers between academics and practitioners, and between agency scientists and managers, are common. Perhaps because of recent radical social changes, which generally acted to level the playing field between groups, South Africa is often thought to be in a better position in this regard than many other countries, but we do need to take heed of any impending rifts. To ensure alignment with implementation possibilities, a robust and vigorous arena of practitioner-led innovation is required; yet, ongoing academic scrutiny is necessary to ensure conceptual soundness. This underlines the necessity for effective sharing between, as an important and relevant example, these two groups.

We believe that applying these five guidelines will go a long way towards maintaining adequate adaptive capacity in SCP in the future.

\section{Conclusion}

This article has highlighted the general similarities between SCP and SAM as applied within SANParks. We consider it artificial to separate these two processes; in practice, they are two parts of the same system. SAM has broader overall applicability to a range of planning, management and decision making situations, whilst SCP is a more focused spatial planning tool for a fairly particular task (i.e. the spatial prioritisation of conservation actions). It is our view that SCP should philosophically be seen as nested inside SAM and that there are significant benefits to approaching SCP as an integral part of a broader adaptive management process, rather than trying to add adaptive components to SCP.

This article has narrated SANParks experiences with SCP over the last decade, specifically reviewing the extent to which these can be considered adaptive in the more formal sense defined by the SAM processes used in the organisation. Comparisons between SCP and SAM showed pervasive underlying similarities, at least based on the SANParks case history reported here. Considerable progress in making SCP more adaptive, particularly given the 'messy' context in which opportunities present themselves for the productive 
use of SCP, was described. Principles were laid out to maintain and enhance this ability to deal with complexity. It is hoped that both SANParks staff and collaborating partners will regard SCP as a venture fully inside the set of adaptive principles.

\section{References}

Berkes, F., Colding, J. \& Folke, C., 2003, Navigating social-ecological systems: building resilience for complexity and change, Cambridge University Press, Cambridge.

Bottrill, M. \& Pressey, R.L., (in prep.), 'Designs for nature: Regional conservation planning, implementation and management', IUCN World Commission on Protected Areas (Best Practice Protected Areas Guidelines Series).

Cadman, M., Petersen, C., Driver, A., Sekhran, N., Maze, K. \& Munzhedzi, S., 2010, Biodiversity for development: South Africa's landscape approach to conserving biodiversity and promoting ecosystem resilience, South African National Biodiversity Institute, Pretoria.

Cilliers, P., 2000, 'What can we learn from a theory of complexity?', Emergence 2(1), 23-33. doi:10.1207/S15327000EM0201_03

Council for Scientific and Industrial Research, 2002, Final Report: Conservation planning framework for the greater Addo Elephant National Park, Council for Scientific and Industrial Research, Stellenbosch.

Cowling, R.M., Pressey, R.L., Rouget, M. \& Lombard, A.T., 2003a, 'A conservation plan for a global biodiversity hotspot: the Cape Floristic Region, South Africa', Biological Conservation 112, 191-216. doi:10.1016/S0006-3207(02)00425-1

Cowling, R.M., Lombard, A.T., Rouget, M., Kerley, G.I.H., Wolf, T., Sims-Castley, R., et al., 2003b, 'A conservation assessment for the Subtropical Thicket Biome', Terrestrial Ecology Research Unit, Port Elizabeth (Report no. 42).

Driver, A., Maze, K., Rouget, M., Lombard, A.T., Nel, J., Turpie, J.K., et al., 2005, National Spatial Biodiversity Assessment 2004: Priorities for Biodiversity Conservation in South Africa, Strelitzia 17, South African National Biodiversity Institute, Pretoria.

Fischer, J., Peterson, G.D., Gardner, T.A., Gordon, L.J., Fazey, I., Elmqvist, T., et al., 2009 , 'Integrating resilience thinking and optimisation for conservation', Trends in Ecology and Evolution 24(10), 549-554. doi:10.1016/j.tree.2009.03.020

Government of South Africa, 2010, National Protected Areas Expansion Strategy, Government Printer, Pretoria.

Grantham, H.S., Bode, M., McDonald-Madden, E., Game, E.T., Knight A.T. \& Possingham, H.P., 2010, 'Effective conservation planning requires learning and adaptation', Frontiers in Ecology and the Environment 8, 431-437. doi:10.1890/080151

Groves, C.R., 2003, Drafting a conservation blueprint: A practitioner's guide to planning for biodiversity, Island Press, Washington DC
Gunderson, L. \& Holling, C., 2001, Panarchy: understanding transformations in human and natural systems, Island Press, Washington DC.

Holness, S.D, Bradshaw, P. \& Brown, A., 2010, Critical biodiversity areas of the Garden Route, Garden Route Initiative, SANParks, Knysna.

Knight, A.T., Cowling, R.M. \& Campbell, B.M., 2006, 'An operational model for implementing conservation action', Conservation Biology 20(2), 408-419. doi:10.1111/j.1523-1739.2006.00305.x, PMid:16903102

Levin, S., 1999, Fragile dominion: complexity and the commons, Helix Books, Boston.

Margules, C.R. \& Pressey, R.L., 2000, 'Systematic conservation planning', Nature 405, 243-253. doi:10.1038/35012251, PMid:10821285

Pressey, R.L. \& Bottrill, M., 2009, 'Approaches to landscape- and seascape-scale conservation planning: convergence, contrasts and challenges', Oryx 43(4), 464475. doi:10.1017/S0030605309990500

Pressey, R.L, Cabeza, M., Watts, M.E., Cowling, R.M. \& Wilson, K.A., 2007, 'Conservation planning in a changing world', Trends in Ecology and Evolution 22(11), 583-592. doi:10.1016/j.tree.2007.10.001

Rogers, K.H., 2005, Biodiversity custodianship in SANParks: a protected area management planning framework, Report to South African National Parks, Pretoria.

Roux, D.J. \& Foxcroft, L.C., 2011, 'The development and application of strategic adaptive management within South African National Parks', Koedoe 53(2), Art. \#1049, 5 pages. doi:10.4102/koedoe.v53i2.1049

Salafsky, N., Margoluis, R., Redford, K.H. \& Robinson, J.G., 2002, 'Improving the practice of conservation: a conceptual framework and research agenda for conservation science', Conservation Biology 16(6), 1469-1479. doi:10.1046/ j.1523-1739.2002.01232.x

SANParks. See South African National Parks.

South African National Parks, 2008, 'Policy context: SANParks' mandate and values', in South African National Parks, A framework for developing and implementing in South African National Parks, A framework for developing and implementing management plans for South African National Parks, viewed 15 Match
http://www.sanparks.org/docs/conservation/cpfjanuary2010.pdf.

Snowden, D.J. \& Boone, M., 2007, 'A leader's framework for decision making', Harvard Business Review November, 69-76.

Stirzaker, R., Biggs, H., Roux, D. \& Cilliers, P., 2010, 'Requisite simplicities to help negotiate complex problems', $A M B I O$ 39(8), 600-607. doi:10.1007/s13280-0100075-7, PMid:21141779

Ulanowicz, R., 2009, The Third Window: Natural life beyond Newton and Darwin, Templeton Foundation Press, West Conshohocken.

Vromans, D.C., Maree, K.S., Holness, S.D., Job, N. \& Brown, A.E., 2010, The Garden Route Biodiversity Sector Plan for the George, Knysna and Bitou Municipalities: Supporting land-use planning and decision-making in Critical Biodiversity Areas and Ecological Support Areas for sustainable development, Garden Route Initiative, South African National Parks, Knysna. 